\title{
Muséologies
}

Les cahiers d'études supérieures

\section{Des jeunes aux commandes du musée ou la médiation revisitée à l'aune des cultures juvéniles}

\section{Maylis Nouvellon}

Volume 8, numéro 2, 2016

Les nouveaux paradigmes

URI : https://id.erudit.org/iderudit/1050767ar

DOI : https://doi.org/10.7202/1050767ar

Aller au sommaire du numéro

Éditeur(s)

Association Québécoise de Promotion des Recherches Étudiantes en Muséologie (AQPREM)

ISSN

1718-5181 (imprimé)

1929-7815 (numérique)

Découvrir la revue

Citer cet article

Nouvellon, M. (2016). Des jeunes aux commandes du musée ou la médiation revisitée à l'aune des cultures juvéniles. Muséologies, 8(2), 179-191.

https://doi.org/10.7202/1050767ar

Tous droits réservés (C Association Québécoise de Promotion des Recherches Étudiantes en Muséologie (AQPREM), 2018
Ce document est protégé par la loi sur le droit d'auteur. L'utilisation des services d'Érudit (y compris la reproduction) est assujettie à sa politique d'utilisation que vous pouvez consulter en ligne.

https://apropos.erudit.org/fr/usagers/politique-dutilisation/ 
Article sept

Des jeunes aux commandes du musée ou la médiation revisitée à l'aune des cultures juvéniles

Maylis Nouvellon 
Maylis Nouvellon, historienne de l'art et muséologue de formation, est doctorante dans le programme muséologie, médiation, patrimoine (École du Louvre, UAPV, UQAM). Ses recherches portent sur le renouvellement des rapports au musée chez les jeunes générations de publics. Elle a enseigné à l'Université Sorbonne Nouvelle-Paris 3 dans le master Muséologie et nouveaux médias. Co-fondatrice, avec Noémie Couillard, du bureau d'études Voix / Publics, elle collabore régulièrement avec le département de la politique des publics du Ministère de la Culture et de la Communication pour la mise en œuvre d'enquêtes nationales menées auprès des publics au sein des Musées de France. 
À partir des années 2000, plusieurs musées en France intègrent dans leur programmation des offres culturelles destinées aux jeunes adultes qui prennent le plus souvent la forme d'événements nocturnes, gratuits et réalisés par des jeunes pour leurs pairs. Ces événements sont présentés par leur décalage par rapport à une visite dite " traditionnelle " : ils " proposent une expérience nouvelle du musée ${ }^{1}$ ", "une visite hors norme ${ }^{2}$ ", « loin des codes de la visite classique $^{3}$ ". Durant ces soirées, la médiation porte moins sur les collections qu'elle ne vise à promouvoir une visite muséale plus ludique, créative et participative. Les visiteurs sont invités à (re)découvrir le musée et ses collections dans des relectures thématiques variées, au travers de jeux et de performances artistiques. Chaque fois, ces événements font la part belle à la créativité et à l'expression des visiteurs : ces derniers sont appelés à participer aux animations imaginées pour eux ou à intervenir directement dans la conception, l'organisation et l'animation de ces événements. Par leur format, ces événements se situent au carrefour de plusieurs tendances actuelles telles que l'événementialisation du musée, l'appel à la participation des visiteurs, l'offre d'expériences muséales divertissantes.

Nombre d'observateurs ont exprimé leurs craintes par rapport à ces tendances qui ont conduit différents musées à proposer des offres " présent[ant] non seulement des choses à observer et à apprendre, mais [aussi] des expériences multisensorielles qui incluent souvent un élément de divertissement ${ }^{4}$ ". Ce courant, analysé par certains en termes de " spectacularisation ${ }^{5}$ ", serait l'indice de l'intégration du musée dans la nouvelle économie d'expériences ${ }^{6}$. Le musée céderait alors à la demande populaire pour affronter le marché concurrentiel des loisirs : il ne s'adresserait plus à un public, mais à des consommateurs d'expériences et se dévoierait de ses missions constitutives en érigeant le divertissement ou la convivialité comme seules finalités de la visite. La critique est ancienne. Elle fonde chez J. Habermas l'opposition de « la culture discutée " par laquelle s'exerce un usage commun de la raison donnant alors forme à un public et à un espace public, à " la culture consommée " où le faire ensemble, l'activité de groupe, résume l'usage des biens culturels sans jamais susciter aucun public ${ }^{7}$.

En nous appuyant sur l'analyse d'un corpus de programmations dédiées aux jeunes adultes dans les musées labellisés "Musées de France " et les résultats d'une étude de réception menée auprès des publics de l'une d'entre elles, nous montrerons que ces offres relèvent d'une approche plus compréhensive des publics qui, loin d'opposer culture et divertissement, acte des évolutions du rapport à la culture et aux savoirs au sein des jeunes générations de publics. Ces événements, par leur format, donnent en effet prise sur la visite de musée en l'ancrant dans une dimension de sociabilité et en invitant les publics à réinventer des liens avec les collections. En cela, ces programmations s'intègrent dans une évolution de la médiation culturelle par laquelle le musée n'est plus seulement envisagé comme une somme d'objets patrimoniaux et de savoirs à transmettre, mais aussi comme un lieu où se tissent des liens sociaux et comme un outil dont chacun peut se saisir pour construire ses propres voies de filiation avec le patrimoine.
1 [Nocturnes+] au MuCEM à Marseille.

2 Nocturne étudiante au musée des Augustins à Toulouse.

3 Étudiants, osez le musée! au musée de Grenoble.

4 MONTPETIT, Raymond. "Expositions, parcs, sites: des lieux d'expériences patrimoniales ". Culture et Musées. vol. 5, $\mathrm{n}^{\circ} 1,2005$, p. 127.

5 MAIRESSE, François. Le musée, temple spectaculaire: une histoire du projet muséal. Lyon: Presses universitaires de Lyon, 2002 ; CHAUMIER, Serge. «Du musée au parc d'attraction, Introduction au numéro thématique ". Culture et Musées. vol. $5, \mathrm{n}^{\mathrm{o}} 1,2005$, p. 13-36.
6 MONTPETIT, art.cit., p. 111.

7 HABERMAS, Jürgen. L'espace public: archéologie de la publicité comme dimension constitutive de la société bourgeoise, trad. par Marc Buhot de Launay. Paris: Payot, p. 167 et 171. 


\section{Le musée face aux cultures juvéniles}

Au début des années 1990, le musée du Louvre récemment rénové inaugure une nouvelle politique des publics à destination des jeunes. Une série d'enquêtes menées à la réouverture du musée montrait en effet que la forte présence des 18-25 ans dans les salles était surtout imputable à la multiplication des visites par les étudiants en $\operatorname{arts}^{8}$. En dehors de ces aficionados, les jeunes pris dans leur ensemble constituaient surtout un public de visiteurs occasionnels dont la fréquentation avoisinait les moyennes nationales ${ }^{9}$. Par ailleurs, une enquête sur les pratiques et représentations des musées d'art chez les jeunes mettait en exergue toute l'ambivalence du rapport au musée chez ces publics. Plus sensibilisés à la visite de musées que les générations précédentes, notamment sous l'effet des incitations scolaires, les jeunes exprimaient un intérêt marqué pour cette pratique. Néanmoins, ils déploraient le manque d'information et d'accompagnement au sein des musées et l'éloignejeune. Pour eux, l'image de la visite muséale était " souvent liée à celle de l'école, avec une connotation d'obligation, d'utilité, voire d'ennui ${ }^{10}$ ". L'enquête montrait que la représentation d'un musée parascolaire s'incarnait plus particulièrement dans les visites-conférences que ces jeunes décrivaient " comme passablement ennuyeuses, statiques, vieillottes, plutôt rebutantes et peu stimulantes ${ }^{11}$ ".

8 D'après l'enquête de l'observatoire des publics mis en place en 1994, les étudiants des formations artistiques visitaient en moyenne cinq fois plus que d'autres jeunes en une année. Voir FOURTEAU, Claude. " La carte Louvre jeunes pour fidéliser un nouveau public ". La Lettre de l'OCIM, ${ }^{\circ} 47$, 1996, p. 22.

9 GUÉRIN, Catherine. « Nocturnes gratuites en octobre au musée du Louvre pour les étudiants ». Publics et Musées. vol. 5, $\mathrm{n}^{\circ} 1,1994$, p. 122.

10 FOURTEAU, art. cit., p. 22.

11 CASANOVA, Françoise. "Une pratique interactive orale de l'histoire de l'art au musée du Louvre: des jeunes s'entretiennent ". Publics et Musées. vol. 14, nº 1, 1998, p. 71. 12 OCTOBRE, Sylvie. "Les 6-14 ans et les équipements culturels à la construction des goûts ». In. DONNAT, Olivier et Paul TOLILA (dir.). Le(s) public(s) de la culture: politiques publiques et équipements culturels. Paris: Presses de Sciences Po, 2003, vol. 2, p. 75 .
Ce constat formulé au musée du Louvre est étayé par la recherche sur les pratiques culturelles des jeunes générations. Comme le montre Sylvie Octobre, ces générations n'ont pas seulement grandi avec la démocratisation d'Internet, elles ont également effectué leur scolarité alors que se multipliaient les politiques de démocratisation culturelle. Celles-ci ont permis d'augmenter le niveau de connaissances et de fréquentation des musées chez les enfants et adolescents ${ }^{12}$, mais leurs effets semblent plus limités sitôt la période de scolarisation passée. Au moment de la jeunesse adulte, il apparaît que la visite scolaire de musée, qu'elle ait été occasionnelle ou régulière, ne se traduit pas mécaniquement dans une appétence pour cette pratique ${ }^{13}:$ «la pédagogisation des activités culturelles sert certes leur démocratisation obligée puisque les élèves sont des publics captifs, mais rarement la construction durable d'un goût pour l'activité ${ }^{14}$ ". Plus globalement, plusieurs sociologues soulignent la distance prise par les jeunes générations à l'égard de la culture scolaire ${ }^{15}$ opérant chez eux une " disjonction entre culture et savoir ${ }^{16}$ ". L'éclectisme de leurs univers culturels en témoigne: à la " culture cultivée " découverte notamment à l'école, ces jeunes allient des goûts pour des objets plus médiatiques issus des industries culturelles qui diffusent au sein des réseaux de sociabilité entre pairs. Les jeunes générations font ainsi montre d'une appétence pour « des propositions qui mêlent registres sérieux et

13 GOTTESDIENER, Hana et Jean-Christophe VILATTE. L'accès des jeunes adultes à l'art contemporain: approches sociologique et psychologique du goût des étudiants pour l'art et de leur fréquentation des musées. Paris: Ministère de la culture et de la communication, 2006, p. 65.

14 OCTOBRE, Sylvie. «Pratiques culturelles chez les jeunes et institutions de transmission: un choc de cultures?". Culture prospective, $\mathrm{n}^{\circ}$ 1, 2009, p. 7.

15 DONNAT, Donnat. Les Français face à la culture: de l'exclusion à l'éclectisme. Paris: La Découverte, 1994 ; LAHIRE, Bernard. La culture des individus: dissonances culturelles et distinction de soi. Paris: La Découverte, 2006; OCTOBRE, Sylvie. Deux pouces et des neurones: les cultures juvéniles de l'ère médiatique à l'ère numérique. Paris: la Documentation Française, 2014.

16 Sylvie Octobre, op. cit., p. 93. 
ludiques, aux frontières du divertissement et de la culture ${ }^{17}$ ", appétence à laquelle les musées tentent de répondre dans des événements qui leur sont dédiés.

Afin d'attirer les publics jeunes et de renouveler l'image qu'ils ont de la visite muséale, le musée du Louvre propose ainsi un nouveau rendez-vous, les Nocturnes du vendredi, auxquelles les moins de 26 ans accèdent gratuitement. Outre la gratuité, ces Nocturnes sont assorties d'une médiation et d'une programmation spécifiques. Premièrement, il s'agit d'inviter des étudiants à réaliser la médiation d'œuvres. Cette proposition intitulée Les jeunes ont la parole (JOP) vise à offrir des « "visites à la carte”, sous forme d'un dialogue, facilité par la similitude des âges ${ }^{18}$ ". Lors des Nocturnes $d u$ vendredi, des étudiants-médiateurs, identifiables à leur tee-shirt aux couleurs des JOP, sont ainsi postés à divers endroits du musée: ils attendent ou sollicitent les visiteurs, jeunes ou non, pour dialoguer sur l'œuvre qu'ils ont choisi de présenter. Cette forme de médiation est dite " conversationnelle " en ce qu'elle

"repose sur les aller et retour effectués entre les participants, sur la place non dominante de l'intervenant, et sur l'égalité de principe entre les participants. Les relations y sont de type horizontal. Le mode conversationnel se distingue du mode conférentiel en ce qu'avant tout échanges et apprentissages des savoirs y sont indissociables ${ }^{19} \mathrm{~m}$.

Pour se démarquer de la visite-conférence, il est conseillé aux étudiants-médiateurs de ne pas lire ou réciter les textes qu'ils ont préalablement écrits et d'éviter autant que possible qu'un trop grand nombre de visiteurs ne se rassemble autour d'eux pendant leurs interventions. Il s'agit avant tout de favoriser la relation interpersonnelle entre le visiteur et l'étudiant-médiateur, d'inciter ce dernier à ajuster en permanence son discours à son interlocuteur, le tout dans un rapport d'égal à égal ${ }^{20}$. En 2013, les JOP proposaient par exemple le thème "Que vois-tu? " : l'interpellation du visiteur et l'invitation à exprimer sa propre perception des œuvres devaient ainsi constituer l'amorce du discours des étudiants-médiateurs.

Le second versant de la programmation des Nocturnes du vendredi tient à la dimension créative que celles-ci introduisent dans le rapport à l'œuvre. En plus des médiations conversationnelles, des artistes sont régulièrement invités à intervenir dans les salles lors de ces soirées. Comédiens, danseurs, musiciens, circassiens... y présentent des performances inspirées des œuvres. Le musée devient alors de façon manifeste un lieu d'inspiration et de création, de "dialogue entre la création contemporaine et [les] collections " par lequel les publics peuvent «le temps d'un soir, pren[dre] part à une véritable métamorphose du Louvre! ${ }^{21}$ ". Cette dimension créative s'exprime également dans les médiations proposées par les jeunes: en 2013, aux côtés des étudiants en histoire des arts, interviennent des étudiants d'arts appliqués. Ces derniers présentaient une de leurs créations inspirées de l'œuvre commentée. Reconstituer l'ambiance sonore d'une marine par un dispositif audio, inviter les visiteurs à retracer de mémoire les grandes lignes de l'œuvre de Wallerant Vaillant, Le petit dessinateur, ou bien encore, au sujet de La dentellière de Vermeer, présenter des broderies selon des techniques traditionnelles ou avec des matériaux contemporains comme le plastique: le dialogue instauré entre les arts fonctionne alors comme dispositif de médiation pour approfondir le regard sur l'œuvre ou pour l'apprécier sous un autre angle.

À partir des années 2000, ces programmations vont essaimer sur l'ensemble du territoire national français. Au total, 37 événements destinés à des publics jeunes adultes (étudiants
17 Ibid.

18 GUÉRIN, art.cit., p. 123.

19 CASANOVA, Françoise. "La voix de musée? Le problème des voix dans la médiation de l'œuvre d'art in situ ". MEI, Médiation et information. $\mathrm{n}^{\circ}$ 9, 1998b, p. 100.
20 Ibid., p. 101.

21 Nocturnes du vendredi, février 2012 sur le thème "Amour à mort". 
ou moins de 26 ans $^{22}$ ) sont ainsi organisés par 60 musées labellisés « Musées de France ${ }^{23}$ ". Ils reprennent dans les grandes lignes les principes des Nocturnes du musée du Louvre au point qu'une formule d'adresse aux jeunes adultes semble se cristalliser dans les musées. En effet, dans tous ces événements, la sollicitation des étudiants est de rigueur : ces derniers sont les coorganisateurs de l'événement et de sa programmation ou les médiateurs et performeurs de la soirée. De même qu'au musée $\mathrm{du}$ Louvre, les animations sont une invitation à découvrir ou à redécouvrir les collections en mêlant aux visites que l'on dira, faute de mieux, « traditionnelles », des visites sur le mode conversationnel parfois présentées comme des " visites éclair ${ }^{24}$ ", des " commentaires express ${ }^{25}$ ", ou « improvisés ${ }^{26}$ ". Le croisement des arts y est également de mise: principalement par l'organisation de concerts (tous genres confondus: musique classique, jazz, rock, musiques électroniques, fanfares, etc.), de performances théâtrales, littéraires (lectures, slam, etc.), de danse... À cette première formule, des musées ont ajouté quelques ingrédients supplémentaires propres à camper une ambiance " festive ", " conviviale ", " chaleureuse $^{27}$ " : il est par exemple souvent possible de prendre un verre ou de manger un bout sur place lors de ces soirées. Les activités dans les salles ont été diversifiées: on propose de (re)découvrir les collections dans des relectures thématiques plus ou moins incongrues (le voyage, la jeunesse, les amours, la lumière, les super-héros, etc.), de participer à des ateliers photographiques, radiophoniques,

22 La population étudiante constitue la catégorie la plus souvent ciblée par ces programmations. Quelques établissements s'adressent toutefois à une tranche d'âge: majoritairement, comme au musée du Louvre, aux moins de 26 ans, quelques fois aux moins de 30 ans (au musée du quai Branly à Paris, au musée des Augustins à Toulouse) et plus rarement aux moins de 35 ans (au musée d'Orsay à Paris). Pour plus de détails sur ces choix de segmentation des publics, voir NOUVELLON, Maylis. "Le musée autrement: catégorisations des publics et des usages du musée ». Poli, nº 12, 2016, p. 68-75.

23 Certains événements sont communs à plusieurs musées. C'est le cas à Strasbourg où les Nuits des étudiants sont organisées tour à tour par l'un des dix musées de la ville. C'est également le cas d'Une nuit Six musées proposant une nocturne commune aux six musées de Nancy ou de Mars aux musées à Nice proposant pendant un mois différents événements dans l'ensemble des musées de la ville. de se déguiser, de prendre part à des jeux de rôle grandeur nature souvent sur le format de l'enquête au musée, ou à des jeux de plateau que certains musées mettent en scène sous la forme d'un speed dating ${ }^{28}$, etc.

Le décalage par rapport à une visite dite « traditionnelle " constitue le leitmotiv de ces programmations et de la communication qui les accompagne. Celle-ci nourrit l'image d'une visite alternative afin de piquer la curiosité des visiteurs potentiels. Les présentations de ces événements multiplient ainsi les formules signifiant que le musée ouvre largement ses portes à la jeunesse pour qu'elle se réapproprie les lieux. À commencer par l'expression du " par et pour les jeunes " présente quasiment dans tous les programmes. "Carte blanche ${ }^{29}$ " leur est donnée pour « investir » le lieu, « s'emparer » de ses collections, " prendre les commandes du musée ${ }^{30}$ " et " concocter une visite sur mesure ${ }^{31}$ ». Dans ces discours, les soirées sont dites " décalées ", " inopinées ", " inattendues ", « insolites ", « inédites » et les publics y sont mis au défi de venir - «Étudiants, osez le musée $!^{32}{ }_{\text {}}$ - dans des interpellations directes et humoristiques:

"Après une dure semaine de cours et de travail acharné (!) le repos t'appelle, mais hors de question de faiblir! Fais honneur à la réputation des étudiants lyonnais: mets de l'ordre dans tes cheveux, un peu de noir sur les yeux, et viens commencer ta soirée au musée ${ }^{33} "$.

24 Nuit des étudiants des musées de la ville de Strasbourg.

25 La nuit des étudiants des musées de la ville d'Angers.

26 Étudiants, osez le musée! au musée de Grenoble.

27 Ces qualificatifs sont récurrents dans les discours présentant les programmes de ces soirées.

28 Lors de la première des [Nocturnes+] au MuCEM ou encore lors des Soirées inopinées du Musée-Aquarium de Nancy.

29 Carte blanche aux étudiants à la Cité de l'architecture et du patrimoine, Épatez la galerie au Musée national du Château de Compiègne, Nuit étudiante au Musée Granet d'Aix-en-Provence.

30 Nocturne étudiante au Musée Magnin à Dijon.

31 Nocturne étudiante au Musée des beaux-arts de Lyon.

32 Nom de l'offre pour les étudiants au musée de Grenoble.

33 Nocturne étudiante au Musée des beaux-arts de Lyon. 
Sur le papier, ces programmations et les discours qui les entourent peuvent soulever des questions sur le statut accordé aux collections dans ces événements, en laissant penser que le musée ne serait plus qu'un simple décor pour des expériences divertissantes. La réalité est différente et l'organisation de ces événements en atteste. Les jeunes invités à intervenir comme médiateurs ou performeurs sont le plus souvent des étudiants issus de formations qui ont trait aux collections présentées dans le musée ou à ses activités. Dans quelques musées, l'appel à participer à la médiation est ouvert à toutes les formations disciplinaires: en «s'appuyant tout autant sur leur formation universitaire que sur leur sensibilité personnelle ${ }^{34}$ " tous les étudiants peuvent devenir médiateurs d'un soir et porter sur les collections " le regard, parfois surprenant, de leur discipline ${ }^{35}$ ". Que les jeunes médiateurs soient recrutés parmi de futurs professionnels de la culture ou plus largement, leurs interventions font l'objet d'un encadrement par les professionnels : il est ainsi précisé que leurs " médiations [sont] de qualité 36 ", que les étudiants-médiateurs ont reçu une formation préalable $^{37}$, qu'ils intègrent " une équipe qui [les] aid[e] à construire [leur] projet ${ }^{38}$ " ou que leur discours est approuvé par les équipes du musée et testé dans un exercice de " mise en médiation ${ }^{39}$ ". Par ces discours, les professionnels des musées réaffirment leur rôle de garant de l'institution et de ses missions.

\section{Le décalage du point de vue des publics}

Quel écho ce discours du décalage trouve-t-il auprès des visiteurs de ces programmations? Et comment ce décalage joue-t-il sur la relation qui se tisse entre le musée et ces jeunes publics? Pour apporter des éléments de réponse à ces deux questions, nous avons mené une étude de réception au sein d'un des musées de beaux-arts de notre corpus. Dans celui-ci, plusieurs soirées sont dédiées aux jeunes pendant un mois : deux d'entre elles présentent des performances théâtrales à partir de textes écrits et joués par des étudiants, une autre propose de mener une enquête au musée sous le format d'un jeu de rôle grandeur nature conçu et animé par une association culturelle locale. L'enquête a eu lieu en 2014 auprès des publics de ces trois soirées.

Les visiteurs de ces trois soirées étaient recontactés dans les jours suivant leur venue pour un entretien portant sur leur perception de ces événements. En premier lieu, nous leur demandions de raconter leur visite en détaillant ce qui les avait marqué, ce qui leur avait plu ou déplu. Il s'agissait avant tout de voir si ces visiteurs évoquaient spontanément ce décalage, promu par l'institution, entre ces soirées et des visites muséales en contexte ordinaire. À l'issue de ce récit, nous les amenions à contextualiser leur participation à ces soirées: comment en avaient-ils entendu parler, qu'est-ce qui les avait motivés à venir, étaient-ils accompagnés, etc. Dans un second temps, ils étaient invités à s'exprimer sur les différentes composantes de ces soirées: le caractère nocturne de ces programmations, leur gratuité, le fait qu'elles s'adressent aux jeunes, que ces derniers y prennent la parole et animent le musée, qu'il y ait des animations de ce type dans le musée. Enfin, une série de questions portaient d'une part sur leurs habitudes de visite - étaient-ils déjà venus dans ce musée et à quand remontait leur dernière visite s'ils n'étaient pas primo-visiteurs, quelles étaient leurs habitudes de visite pendant l'enfance, avaient-ils effectué des visites dans l'année écoulée et dans quel contexte (en visite libre ou lors d'un événement) - et, d'autre part, sur

39 Entretien auprès de la chargée des publics étudiants d'un musée de beaux-arts. Une campagne d'entretien auprès des professionnels a été menée dans ce musée de beaux-arts préalablement à la réalisation d'une étude de réception de la programmation que ce musée dédie aux jeunes et sur laquelle nous revenons ci-après.
34 Nocturne étudiante au Musée des beaux-arts de Lyon.

35 Les jeunes ont la parole d'avril 2016 au musée du Louvre.

36 Mars aux musées, dans les musées de la ville de Nice

<http://www.marsauxmusees.fr/> (consulté en mars 2016).

37 Les jeunes ont la parole au musée du Louvre.

38 Appel à participation du musée de Grenoble, à l'occasion de l'événement Étudiants, osez le musée! <http://www.museedegrenoble.fr/966-etudiants.htm> (consulté en mars 2016). 
leur profil socioculturel (situation professionnelle, profession ou domaine d'étude, âge, lieu de résidence, professions des parents).

Au total, 27 entretiens ont ainsi été recueillis auprès de 16 femmes et 11 hommes, âgés de 19 à 29 ans, le plus souvent des étudiants.

La majorité de ces visiteurs étaient déjà venus dans ce musée, mais le plus souvent ces visites étaient anciennes. De même, une majorité des répondants avaient visité des musées dans l'année écoulée, plus souvent à l'occasion de déplacements touristiques que dans la ville où ils résident. Enfin, les deux tiers des répondants découvraient ces programmations dédiées aux jeunes le soir où ils ont été rencontrés.

Les résultats que nous présentons dans la suite de cet article ont trait dans un premier temps à ce que les visiteurs ont exprimé au sujet des animations proposées: quel est, selon eux, leurs apports dans la découverte du musée et de ses collections? Dans un second temps, nous nous attachons aux propos des visiteurs qualifiant musée: comment ces programmations conçues par et pour les jeunes jouent sur la relation qui se tisse entre ces publics et le musée?

\section{Une visite alternative... aux collections?}

Cette étude de réception confirme la place centrale des collections dans les animations proposées. En effet, lorsque nous avons demandé à nos interlocuteurs de raconter leur visite, la découverte des œuvres et du musée y est autant mentionnée que le caractère ludique de ces soirées. Plusieurs visiteurs ont commencé le récit de leur expérience en comparant ces soirées à d'autres formes de visites, notamment aux visites en contexte ordinaire. Par comparaison, ces soirées « ça apportait une petite touche moins austère, on va dire, au musée et à la façon de voir les œuvres "; "c'était vraiment plein d'interprétations, donc très plaisant, et donc, ouais, c'était un très bon moment qui changeait d'une visite normale "; "c'est pas juste une visite comme on a l'habitude d'en voir généralement, c'est quelque chose de très ludique ". Si la dimension ludique

teinte fortement leur expérience muséale, les visiteurs ne se méprennent pas pour autant sur les intentions des concepteurs de ces soirées. Dans leurs récits de visite, ils témoignent du fait que les moyens mis en œuvre (théâtre, jeux) ne prennent pas le pas sur la finalité de ces soirées: découvrir le musée et ses collections. Ainsi dans les propos des visiteurs, tout comme dans les présentations que les musées font de ces soirées, la visite ludique ne s'oppose pas à la visite studieuse. À ce titre, il est remarquable de voir que les formules de discours par lesquelles les musées communiquent sur ces événements réapparaissent de façon symétrique dans les entretiens avec les visiteurs. En témoignent les propos de cette jeune femme découvrant pour la première fois le musée lors d'une soirée dédiée et qui en commente les animations en ces termes:

" Ça amène un nouveau regard un peu hors des sentiers battus, un peu... parce que là leur regard était pas du tout celui d'un historien de l'art ou d'un... ou d'un guide traditionnel qui aurait été formé, c'était une approche différente, un peu basée sur les connaissances qu'ils avaient par rapport à ça, des connaissances qu'ils ont recherchées et puis aussi sur leur sensibilité. Et puis ça amène un peu... enfin une relation d'égal à égal c'est peut-être un peu fort, mais enfin, ça ressemble moins à une leçon, ça ressemble plus à une discussion entre amis à propos de telle œuvre et qui apporte certaines choses, ça ressemble pas forcément à une leçon au sens strict. "

Ainsi, les animations proposées, loin de détourner l'attention des collections, sont estimées par les visiteurs pour leur capacité à les mettre en valeur. Elles provoquent l'arrêt devant les œuvres et approfondissent le regard sur elles:

"J'ai trouvé très intéressant que ça mette en avant quelques œuvres en particulier $[\ldots]$ ça permet de mieux les apprécier en fait parce que c'est vrai que je suis allée plusieurs fois à ce musée et c'est vrai que je passais devant les œuvres et les voir comme ça on se rend pas toujours compte 
de... on prend pas le temps de les voir et d'en apprendre sur l'œuvre comme le fait la nocturne".

Ces animations désinhibent le rapport aux savoirs et aux œuvres en le rendant moins direct, plus informel: «ça permettait de connaître l'histoire de l'œuvre sans que ce soit très scolaire "; « j’aimais bien comment on nous mettait la culture accessible sans qu'il y ait des tonnes de bouquins à lire "; " il y avait en fait des représentations de personnages liés au lieu [...] et qui reprenaient l'histoire de la peinture, donc, du coup, finalement, indirectement, on apprenait des connaissances sur le tableau ".

La légitimité de ce type d'approches des collections n'est pas remise en cause par les visiteurs que nous avons rencontrés. Néanmoins, ces derniers se montrent vigilants à l'égard de ces animations. Comme l'indique ce visiteur, ils attendent qu'elles instaurent un équilibre entre la dimension ludique et l'apport de connaissance: « il faut qu'ily ait à la fois la visite et le spectacle, il faut pas oublier les œuvres, sinon dans ce cas là on dit qu'on fait simplement une pièce de théâtre dans le musée ". Ainsi, lorsque les animations flirtent avec la fiction, comme c'est plus particulièrement le cas lors de la soirée de jeu de rôles où il s'agissait de mener une enquête dans le musée, la confiance que les visiteurs peuvent accorder au discours muséal est mise à l'épreuve. Le doute pousse alors à chercher confirmation afin de s'assurer que la qualité attendue d'un discours institutionnel n'a pas été escamotée pour les besoins de l'intrigue:

"ça reste quand même une visite faut pas... faut pas... parce que j'ai discuté quand même avec lui après [avec celui qui a conçu et animé la soirée d'enquête au musée] et il m'a dit “tout ce que je vous ai raconté sur les œuvres tout est vrai. Donc je me suis... je me suis juste, j'ai juste créé une histoire autour de ça en partant des pièces qu'il y avait dans chaque salle, mais ça reste que de la vérité”. Donc c'est ça que j’ai aimé, ça aurait juste été une histoire en l'air bon ça aurait été bien pour le théâtre, mais ça aurait été dommage... " pour le musée.

Ces résultats soulignent ainsi que, même dans des approches alternatives des collections, culture et divertissement ne s'opposent pas terme à terme. Comme le souligne Raymond Montpetit,

" que le musée d'aujourd'hui se veuille convivial, interactif et même amusant, qu'il prenne note que ceux qui s'y rendent le font dans leur temps de loisir, n'indique pas, à nos yeux, qu'il offre moins de contenus ni d'occasions de vivre des expériences qui favorisent la réflexion et le développement ${ }^{40}$ ".

Pour les visiteurs que nous avons rencontrés, ces soirées répondent à une attente d'accompagnement au musée et relèvent avant tout d'une médiation culturelle. Leurs animations permettent de désacraliser la visite, de prendre prise sur les collections d'un musée, de guider et d'approfondir le regard sur les œuvres.

\section{Des réappropriations créatives des collections à la dimension sociable de la visite}

Considérons à présent les effets de ces soirées sur la relation musée-visiteur. Car si ces programmations sont avant tout une forme de médiation, elles n'en constituent pas moins une proposition pour renouveler l'expérience muséale en permettant à des acteurs extérieurs aux équipes du musée de se réapproprier les collections lors d'un moment convivial. Ces différentes dimensions des soirées, à la fois participatives, créatives et conviviales, sont relativement indissociables dans les récits des visiteurs: ensemble, elles fondent le caractère novateur de ces programmations et constituent du point de vue des visiteurs une affirmation du rôle social du musée. 
En effet, selon eux, ces programmations signent tout d'abord la volonté institutionnelle de se rapprocher d'une génération que beaucoup ont décrite comme éloignée de cette pratique culturelle: «quand on pense musée faut pas non plus se voiler la face, même [pour] des étudiants ou des jeunes, c'est chiant "; " pour des personnes qui sont un peu réticentes voir qu'il y a un environnement proche de ce qu'ils connaissent et une approche qui va pas entre guillemets leur prendre la tête [...] c'est intéressant parce que justement c'est un public qui a pas forcément l'habitude d'aller au musée ", " ça donne une image bien plus proche de nous et même du musée du coup ".

En ce sens, concernant les deux soirées animées par des étudiants, les visiteurs ont souligné l'intérêt que revêt à leurs yeux cette prise de parole des jeunes. Selon eux, la similitude d'âge avec les publics ou le fait qu'ils ne sont pas (encore) des professionnels démarquent leur intervention de la visite que mènerait un guide professionnel: « on a le stéréotype du guide très vieux, comment dire, très savant et là ça apporte un autre regard "; " cette petite touche jeune ouais ça c'est bien, c'est remettre un peu au goût du jour, voir qu'on peut participer à cet art d'autres manières que... qu'en allant le voir "et c'est gothique, c'est roman, machin"... ". À l'opposé de cette image (préconçue) de la visite guidée, la parole des jeunes leur semble plus adaptée car elle s'adosse à une même culture générationnelle et mobilise des références communes susceptibles de retenir leur attention et de créer une ambiance conviviale: "j'ai adhéré plus facilement à l'humour et aux informations qu'on nous donnait parce que c'était des jeunes ", "ça fait une bonne ambiance aussi, on est un peu tous sur une même longueur d'onde, c'est intéressant, on comprend la même chose ".

Ensuite, ces programmations leur apparaissent comme une légitimation de la parole d'acteurs extérieurs au musée et de nouvelles formes d'appropriation de l'institution. Un visiteur le souligne explicitement: selon lui, il était important que

"quelqu'un qui ne vienne pas du musée puisse prendre la parole et se l'approprier et faire quelque chose qui finalement... parler du musée, mais de manière incongrue $[. .$.$] . C'est chouette qu'on fasse ce$ genre de choses dans des lieux aussi institutionnels qu'on puisse prendre la liberté de les faire autrement, sans chercher à être absolument subversif, mais les faire autrement, c'est important."

En cela, plusieurs visiteurs de ces soirées réalisées par les étudiants considèrent que celles-ci ne transforment pas seulement l'image qu'ils ont du musée, mais qu'elles amendent aussi celle dont peut pâtir la jeunesse : «par rapport à l'image qu'on peut avoir des jeunes ou quoi... c'est vite dit, quelqu'un d'un peu aigri ça va trouver les jeunes voilà ils sont pas dans la culture "; "c'est encourageant peut-être, encourageant, comme quoi des jeunes peuvent faire aussi des trucs bien, de qualité ». À ce titre, quelques-uns regrettent que certaines de ces soirées ne s'adressent qu'aux étudiants ou que leur audience soit limitée: "ça aurait été pas mal aussi de voir que des adultes peuvent aussi venir voir des jeunes présenter des choses dans un musée "; « mais du coup qu'il y ait que 40 personnes... [...] ça le montre, mais c'est très restreint, la portée du fait que ce soit des jeunes ».

Comme le soulignent John H. Falk et Lynn D. Dierking ${ }^{41}$, si l'apprentissage est un motif important de la visite de ces lieux de savoirs, celle-ci ne s'y résume pas. Ainsi, la visite d'un musée peut satisfaire des intérêts culturels qui ne sont qu'indirectement liés à l'histoire des collections elles-mêmes. Ces soirées, par leur dimension participative et créative, donnent alors un temps d'expression aux intérêts personnels des visiteurs par lesquels ils retissent des liens avec les collections. Ces réappropriations créatives des collections fournissent alors une autre voie d'accès au 
musée notamment à ceux pour qui l'amour de l'art n'est pas une motivation suffisante pour visiter. Ainsi de ce visiteur, ancien performeur de visites circassiennes, qui explique: « je veux dire, moi, c'est bête, mais avant de faire la première visite cirque, le musée, avant de faire les repérages, j'étais jamais venu au musée alors que ça faisait déjà quelques années que j'habitais [cette ville] ". Ou de cet autre venu par goût du théâtre lors de la soirée enquêtée et par intérêt " pour l'idée de faire du théâtre hors du théâtre donc dans l'idée déjà ça m'intéressait beaucoup ". À ce titre, lorsque nous leur avons demandé ce qui les avait motivés à venir, les deux tiers des visiteurs interrogés ont expliqué qu'il connaissait quelqu'un qui intervenait ce soir-là, ou qu'il connaissait quelqu'un qui connaissait quelqu'un... selon un effet de boule-de-neige qui traduit la force de ces programmations participatives et créatives pour conquérir de nouveaux publics et mobiliser des réseaux constitués autour d'intérêts communs.

De même, comme le montrent J. H. Falk et L. D. Dierking, la visite muséale peut aussi servir de support aux sociabilités: la motivation à visiter fait alors passer l'intérêt pour les collections au second plan, derrière les relations que cette pratique suscite ou nourrit. En accentuant le caractère convivial de la visite, ces soirées permettent d'ancrer la visite dans cette dimension sociable. En effet, par leur format, ces programmations amplifient les interactions entre les visiteurs et avec les intervenants.

Lorsque des jeux sont mis en œuvre, les dynamiques de coopération qui se mettent en place permettent "d'aller parler à d'autres gens et de partager [ses] questionnements ». De même, la prise de parole des jeunes, apparentée "à une discussion entre amis à propos de telle œuvre ", permet « de pouvoir voir, avec des gens de la même génération, la culture que chacun a et qui est différente "; de " casser aussi le côté un peu trop éloigné presque de l'art parce que moi je suis dans une fac de sciences et c'est difficile de dépasser ça [...] c'est dur d'aller vers des gens qui nous parlent un peu trop d'art ". La visite cesse alors d'être seulement perçue comme une activité studieuse pour être envisagée comme une pratique de sociabilité qu'il est possible de proposer autour de soi, y compris à ceux "qui ne sont pas très musée ": "parce qu'enfin c'est vrai qu'il faut bien le dire les jeunes qui... enfin moi je connais pas forcément énormément de gens à qui je peux dire "est-ce que tu veux aller au musée" enfin voilà... on peut le dire, mais y a pas forcément de réponse positive nécessairement ". Seules cinq personnes parmi les visiteurs interrogés sont venues à la soirée en solitaire. Plusieurs visiteurs ont souligné que ces soirées leur ont permis de partager un bon moment entre amis et quelques-uns racontent qu'ils ont eu l'occasion de rencontrer d'autres visiteurs voire, parfois, de tisser des liens au-delà de la visite.

Ainsi, plusieurs visiteurs font remarquer que ces programmations pourraient être ouvertes plus largement qu'aux étudiants et aux jeunes afin de ne pas entraver la dimension sociable de ces visites. Car l'exclusivité d'accès à ces événements accordée aux étudiants a pu constituer un frein à la venue des amis, non étudiants, de certains visiteurs ou a donné lieu à des tactiques de contournement: ainsi d'un visiteur qui a " réussi " à obtenir une " exception " pour son ami jeune actif, ou cet autre, jeune actif lui-même, ayant " dû un peu feinter " et téléphoner au service de réservation afin d'être " accepté ". S'ils considèrent que l'adresse faite aux jeunes et aux étudiants est un signe de l'ouverture du musée, nos interlocuteurs sont aussi critiques à l'égard de cette catégorisation qui s'apparente pour certains à une forme d'exclusion, "des jeunes qui ont juste le bac " par exemple, voire d'eux-mêmes lorsqu'ils sortiront des catégories ciblées: « voilà moi pareil l'année prochaine je suis plus étudiante et ça veut dire que je suis exclue de toutes les visites étudiantes, non! ça me saoulerait! » Car l'enjeu des programmations dédiées est là : négocier la sortie des catégories cibles pour éviter l'écueil de la frustration et du décrochage. À ce titre, si une moitié de l'échantillon envisage de revenir dans ce musée indifféremment pour une visite en contexte ordinaire ou lors d'un événement, l'autre se déclare plus encline à revenir lors d'un événement du même type. Se pose alors la question de la pérennisation de ces programmations conçues comme " décalées " par les professionnels et néanmoins plébiscitées par les publics. 
Figurant comme l'une des résurgences du thème de la participation des visiteurs ${ }^{42}$, ces soirées se démarquent toutefois des muséologies participatives nées dans les années 1970 avec la nouvelle muséologie ou actuellement au sein des muséologies citoyennes ${ }^{43}$. En effet, ici, les visiteurs ne prennent pas la parole en tant que représentants d'une communauté ou d'un groupe social. Ils interviennent comme membres des publics et leur participation s'affiche avant tout comme l'expression d'un rapport personnel au musée propre à composer ou à recomposer la signification de ces lieux. Plus attachées à l'esprit qu'à la lettre des principes fondateurs de la nouvelle muséologie, ces soirées partagent néanmoins avec ce courant la volonté d'affirmer la fonction sociale du musée. Elles déplacent alors le rôle traditionnellement dévolu à la médiation et aux professionnels des publics: ceux-ci se décentrent en effet de la fonction de vulgarisation des savoirs sur les collections pour adopter un rôle d'activation et d'accompagnement de ces réappropriations ${ }^{44}$. En invitant à s'inspirer des contenus du musée voire à les remixer, en provoquant les échanges entre les visiteurs, sur les collections ou à partir d'elles, ces soirées ne renouvellent pas à proprement parler l'expérience muséale, mais rendent visible la nature variée de cette expérience, à la fois cognitive et sensible, mais aussi, et peut-être avant tout, sociale. En cela, elles contribuent à légitimer les appropriations ordinaires de la visite habituellement tapies dans la sphère privée des visiteurs ou émergeant ponctuellement dans les enquêtes de publics.
42 CHAUMIER, Serge. "Musées, encore un effort pour être participatifs! ». In. CHEVALIER, Denis et Aude FANLO (dir.). Métamorphoses des musées de société. Paris: La Documentation française, 2013, p. 117-126; COUILLARD, Noémie.

"Les concours photographiques ou les ambiguités de la participation des visiteurs ". In. CHAUMIER, Serge, Anne KREBS et Mélanie ROUSTAN (dir.). Visiteurs photographes au musée. Paris: La Documentation française, 2013, p. 239-250.
43 MEUNIER, Anik et Virginie SOULIER. « Préfiguration du concept de muséologie citoyenne ». In. CARDIN, JeanFrançois et al. (dir.). Histoire, musées et éducation à la citoyenneté. Québec: Éditions Multimondes, 2010, p. 309-328. 44 Concernant cette évolution de la médiation culturelle, voir CHAUMIER, Serge et François MAIRESSE. La médiation culturelle. Paris: A. Colin, 2013, p. 115-146. 


\section{Youth in command at the museum or mediation practices revisited in the light of youth culture.}

Since the beginning of the twenty-first century, a number of French museums have developed specific programs to address the young adult public. Playful and entertaining, creative and participatory, these programs offer a distinct alternative to a so-called "traditional" visit of a lecture type. In these museums, they embody an evolution through which they decentralize their collections and turn more broadly toward the public and the variety of their museal experiences. We will focus on a corpus of these programs at the museums of France and on the results of a reception survey conducted with visitors at one of the museums and in order to demonstrate that these visits are not just entertainment that is shifting away from its collections. Rather, these visits respond to a twofold expectation of the younger generation of the public: an expectation of outreach on one hand, and, on the other, of a legitimization of more informal approaches to the collections and related knowledge. 